\title{
Erratum to: Numerical and Experimental Investigation of the Grain Refine- ment of Liquid Metals through Cavitation Processing
}

\author{
R. Haghayeghi ${ }^{1, *}$, E. Ezzatneshan ${ }^{2}$, H. Bahai ${ }^{3}$, and L. Nastac ${ }^{4}$
}

Erratum to : Met. Mater. Int., Vol. 19, No. 5 (2013), pp. 959 967

DOI: 10.1007/s12540-013-5008-0

Following the authors' request, there is a change in the authorship of the article "Numerical and Experimental Investigation of the Grain Refinement of Liquid Metals through Cavitation Processing", in Metals and Materials International, Vol.19 (2013) pp.959-967. The second and third authors clarified that they had no knowledge on the source and use of the data and the figures appeared in the paper, and requested the removal of their name from the author list. The corresponding author agreed the removal of the second and third authors' name from the author list.

\section{Before correction}

R. Haghayeghi ${ }^{1, *}$, E. Ezzatneshan ${ }^{2}$, H. Bahai ${ }^{3}$, and L. Nastac ${ }^{4}$ ${ }^{1}$ Department of Materials Engineering, Science and Research Branch, Islamic Azad University, Tehran, Iran

${ }^{2}$ Sharif University of Technology, Aerospace Engineering Department, Tehran, Iran

${ }^{3}$ Brunel University, School of Engineering and Design, Uxbridge, Middlesex, UB8 3PH, UK

${ }^{4}$ The University of Alabama, Department of Metallurgical and Materials Engineering, Tuscaloosa, AL 35487-0202, USA

\section{After correction}

\section{R. Haghayeghi ${ }^{1, *}$ and L. Nastac ${ }^{2}$}

${ }^{1}$ Department of Materials Engineering, Science and Research Branch, Islamic Azad University, Tehran, Iran

${ }^{2}$ The University of Alabama, Department of Metallurgical and Materials Engineering, Tuscaloosa, AL 35487-0202, USA

The online version of the original article can be found at http://dx.doi.org/ doi: 10.1007/s12540-013-5008-0

CKIM and Springer 